\title{
Correction to: Prioritising the development of severity distributions in burden of disease studies for countries in the European region
}

\author{
Grant M. A. Wyper ${ }^{1 *}$, lan Grant ${ }^{2}$, Eilidh Fletcher ${ }^{2}$, Neil Chalmers ${ }^{1}$, Gerry McCartney ${ }^{1}$ and Diane L. Stockton ${ }^{1}$
}

\section{Correction to: Arch Public Health (2020) 78: 3 https://doi.org/10.1186/s13690-019-0385-6}

In the original publication of this article [1], the author pointed out the legends of Figs. 1 and 2 are not entire. The correct legends are:

Fig. 1 Rescaling severity distributions that include asymptomatic cases to obtain symptomatic severity distributions. Example derived using GBD 2016 global health state prevalence estimates for cocaine dependence

Fig. 2 Potential variation in disability weight for the 20 leading non-communicable diseases of YLD in the European region, 2017. YLD denotes Years Lost to Disability; 20 leading causes based on ranking of YLD rate for the European region; Non-communicable diseases only; Causes ordered ascendingly according to the number of YLD

The publisher apologizes to the readers and authors for the inconvenience.

\section{Author details}

${ }^{1}$ Public Health Science Directorate, NHS Health Scotland, Meridian Court, 5 Cadogan Street, Glasgow, Scotland G2 6QE. ${ }^{2}$ Information Services Division, NHS National Services Scotland, Gyle Square, 1 South Gyle Crescent,

Edinburgh, Scotland EH12 9EB.
Published online: 02 April 2020

\section{Reference}

1. Wyper GMA, et al. Prioritising the development of severity distributions in burden of disease studies for countries in the European region. Arch Public Health. 2020;78:3 https://doi.org/10.1186/s13690-019-0385-6.

The original article can be found online at https://doi.org/10.1186/s13690019-0385-6

*Correspondence: gwyper@nhs.net

'Public Health Science Directorate, NHS Health Scotland, Meridian Court, 5 Cadogan Street, Glasgow, Scotland G2 6QE

Full list of author information is available at the end of the article

C C The Author(s). 2020 Open Access This article is licensed under a Creative Commons Attribution 4.0 International License, which permits use, sharing, adaptation, distribution and reproduction in any medium or format, as long as you give appropriate credit to the original author(s) and the source, provide a link to the Creative Commons licence, and indicate if changes were made. The images or other third party material in this article are included in the article's Creative Commons licence, unless indicated otherwise in a credit line to the material. If material is not included in the article's Creative Commons licence and your intended use is not permitted by statutory regulation or exceeds the permitted use, you will need to obtain permission directly from the copyright holder. To view a copy of this licence, visit http://creativecommons.org/licenses/by/4.0/ The Creative Commons Public Domain Dedication waiver (http://creativecommons.org/publicdomain/zero/1.0/) applies to the data made available in this article, unless otherwise stated in a credit line to the data. 